\title{
Efficiency of Extraction of Trace metals from Blood samples using Wet Digestion and Microwave Digestion Techniques
}

\author{
${ }^{* 1}$ M. I. YAHAYA; A. SHEHU; F.G. DABAI \\ Department of Applied Chemistry, Federal University Dutsin - Ma, Katsina State, Nigeria \\ Biology Department, Kebbi State College of Basic and Advanced Studies, Yauri, Nigeria \\ Chemistry Department, Kebbi State College of Basic and Advanced Studies, Yauri, Nigeria
}

Mobile: +234 7037928905

\begin{abstract}
The efficiency of extraction of trace metals using conventional wet acid digestion method (CDM) and microwave induced acid digestion method (MWD) was determined by recovery experiments. The high percentage recoveries obtained from microwave induced acid digestion method make it to be a more efficient method than the conventional wet acid method. The conventional wet acid digestion method is time consuming while the MWD method saves time, less than four minutes are required to complete the digestion of the biological samples in this study. CJASEM
\end{abstract}

\section{http://dx.doi.org/10.4314/jasem.v17i3.4}

Recent developments in instrumentation have lowered the limits for determining many trace elements to the low nanogram or even picogram range, thus enabling determination of parts per billion and in some cases, even less (Becking et al. 2007). The present needs for trace measurements and techniques for micro and sub microanalyses were already substantial and recent reports indicate that the requirements and demands for such capabilities will increase considerably, because most essential trace metals are present in biological specimens in very low concentrations, precise and accurate analysis is most essential if meaningful results are to be obtained. (Ananth, 2005; Yenagisawa and Wada, 2002).

Advance in analytical capabilities have made it possible to detect lower and lower levels of these contaminants in human down to parts per trillion and lower so that new compounds are identified regularly and older compounds continue to be detected even though these chemicals are no longer in use and even when their levels have declined drastically (Guidotti et al. 2008). The significance of these detections can only be understood by looking at how these levels have changed over time and how the concentrations compare to those considered capable of causing adverse health effects in human studies of contaminants in the food supply. Direct measurements of human fluids and tissues; reveal that the levels of contaminants of concern, such as lead have declined more than $90 \%$ in the general populations during the past few decades. The decline appears to be continuing but at a slower rate (Lindh, 2005; Thomas, 2002). These studies also reveal that, there are some special populations that continue to show high levels of contamination, generally because of local use of the chemical of concern (Michael, 2003). Also comparison of the current low levels with the lowest levels thought to be of concern by international and national regulatory agencies reveals that the trace amounts in human are well below the level of concern for the general public.

In recent years, awareness that trace element s play a very important role, either beneficial or harmful, in human health has increased (Ogunfowokan et al. 2009). Many metabolic disorders in man are accompanied by alterations in the concentration of one or more trace elements in some body fluid, especially blood serum or plasma. Interest in trace element research in clinical medicine, biology environmental studies, toxicology and nutrition has become an exciting frontier and during the last two decades the number of publications on their subject has progressively increased. (Barany et al. 2002)

The relation between trace elements and human health has been studied scarcely (Ogunfowokan et al. 2008). The studies are more concentrated towards the biochemical changes caused by an increased intake of metals in relation to alteration of metal metabolism and our understanding of mechanisms of toxicology of metals remain obscure. Digestion of biological materials is very important for trace element determinations hence the need for the present study that determines the efficiency of extraction of trace metals from blood samples using wet digestion and microwave digestion techniques

\section{MATEARIALS AND METHODS}

Pretreatment of sample containers: All glassware and sample containers (polyethylene plastic bottles) and Teflon beakers were thoroughly washed with non-ionic detergent solution to ensure all dirts were removed followed by rinsing with tap water until free of detergent.

These were thoroughly rinsed with distilled water followed by soaking in $10 \%$ (v/v) nitric acid for 48 hours and finally rinsed with triply distilled water and 
dried in the oven at $80^{\circ} \mathrm{C}$ prior to sampling and analysis.

Digestion using Conventional Wet Acid Method $(C D M)$ : Blood samples were digested by the Conventional Wet Acid Method by adopting the method of Memon et al. (2007). Accurately $0.5 \mathrm{~mL}$ of whole blood was taking into Pyrex flask separately. To this was added $3 \mathrm{~mL}$ of freshly prepared mixture of concentrated nitric acid and hydrogen peroxide $\left[\mathrm{HNO}_{3}-\mathrm{H}_{2} \mathrm{O}_{2}\right](2: 1 \mathrm{~V} / \mathrm{V})$ and stood for 10 minutes. The flasks were covered with watch glass and then digested at $60-70{ }^{\circ} \mathrm{C}$ for $1-2$ hours. The digests were then treated with $2 \mathrm{~mL}$ nitric acid and few drops of $\mathrm{H}_{2} \mathrm{O}_{2}$, while heating continued on hot plate at about $80{ }^{\circ} \mathrm{C}$ until a clear digested solution was obtained. The excess acid mixture was evaporated to semi - dry mass, cooled and diluted with $0.1 \mathrm{~mL}$ nitric acid. These were transferred into $100 \mathrm{~mL}$ volumetric flask and diluted to mark using triply distilled water. A blank extraction (without the sample) was carried out through the complete procedure using triply distilled water.

Digestion using the Microwave induced Acid Digestion Method [MWD]: Blood samples were digested by the Microwave induced acid Digestion Method by adopting the method of Memon et al. (2007) in other to achieve a shorter digestion time. Accurately $0.5 \mathrm{~mL}$ each of whole blood was taking into Pyrex flask separately. Three milliliters of freshly prepared mixture of concentrated nitric acid and hydrogen peroxide $\left[\mathrm{HNO}_{3}-\mathrm{H}_{2} \mathrm{O}_{2}\right](2: 1 \mathrm{~V} / \mathrm{V})$ were added the sample and stood for 10 minutes. Then heated following a one - stage digestion programmed at $80 \%$ of the total power in a Sharp Light - up (Dial) domestic microwave oven with maximum heating power of $800 \mathrm{~W}$ for 3 minutes. After this the digestion flasks were cooled. The resulting solutions were evaporated to semidried mass to remove excess acid, and diluted with $0.1 \mathrm{M}$ nitric acid and transferred into a $100 \mathrm{~mL}$ volumetric flask. This was further diluted to the mark of the volumetric flask using triply distilled water. The worked-up samples were stored in polyethylene containers in a refrigerator at $4{ }^{0} \mathrm{C}$ prior to FAAS analysis. A blank extraction (without the samples) was carried out through the complete procedure using triply distilled water.

Recovery work: To establish the validity of results and reliability of the analytical procedures described in this study, recovery experiment was carried out since certified blood reference materials were not available to us when this study was conducted. Two milliliters of the blood samples were spiked with 10 ppm of $\mathrm{Zn}, \mathrm{Cu}, \mathrm{Cd}, \mathrm{Pb}, \mathrm{Ni}$, and $\mathrm{Fe}$ in separate Teflon beakers and digested, using both CDM and MWD. The digested spiked samples were made up to mark in a $100 \mathrm{~mL}$ volumetric flask with triply distilled water. The worked-up samples were stored in Polyethylene containers at $4^{0} \mathrm{C}$ prior to FAAS analyses. Also a $10 \mathrm{~mL}$ each of $10 \mathrm{ppm}$ of the standards were taken for FAAS analyses so that the results obtained can be compared with those of the spiked blood samples to obtain the recovery. The recovery was done in triplicate

Instrumentation: A Chemtech Analytical Alpha-4 (UK) Flame Atomic Absorption Spectrophotometry (FAAS) available at the Central Science Laboratory, Obafemi Awolowo University, Ile-Ife Nigeria was used to analysed the concentrations levels of the trace metals in the digested matrices. FAAS measurements of the elements were made at the wavelengths and detection limits indicated in Table 1.

The Limits of detection: Limits of detection of the analysed metals - $\mathrm{Zn}^{2+}, \mathrm{Cu}^{2+}, \mathrm{Cd}^{2+}, \mathrm{Pb}^{2+}, \mathrm{Ni}^{2+}$, and $\mathrm{Fe}^{2+}$ - were determined from the quantity of the analytes aspirated into the equipment that gave rise to a reading equal to thrice the standard deviation $(3 \sigma)$ of their lowest detectable concentration from the mean of six replicate analyses by FAAS. The precision was also measured as percentage relative standard deviation of the signal response arising from six determination of $1 \mathrm{mg} / \mathrm{L}$ standard analytes.

Table 1: Selected Wavelengths (nm), Slit Width and Detection Limits for the FAAS Determination of the Elements

\begin{tabular}{|l|l|l|l|}
\hline Elements & Wavelength $(\mathrm{nm})$ & Slit Width & Detection Limits $(\mu \mathrm{g} / \mathrm{mL})$ \\
\hline $\mathrm{Cd}$ & 228.8 & 3 & 0.002 \\
\hline $\mathrm{Cu}$ & 324.7 & 2 & 0.001 \\
\hline $\mathrm{Fe}$ & 248.3 & 1 & 0.003 \\
\hline $\mathrm{Ni}$ & 232 & 1 & 0.005 \\
\hline $\mathrm{Pb}$ & 217 & 3 & 0.004 \\
\hline $\mathrm{Zn}$ & 360.1 & 2 & 0.006 \\
\hline
\end{tabular}


Table 2: Percentage Recoveries of Trace Metals in Blood using Conventional

\begin{tabular}{|l|l|l|l|l|}
\hline Sample & Elements & $\begin{array}{l}\text { Amount } \\
\text { Spiked }(\mu \mathrm{g} / \mathrm{mL})\end{array}$ & $\begin{array}{l}\text { Amount Recovered } \\
(\mu \mathrm{g} / \mathrm{mL})\end{array}$ & $\begin{array}{l}\text { Percentage } \\
\text { Recovery }(\%)\end{array}$ \\
\hline \multirow{3}{*}{ Blood } & $\mathrm{Zn}$ & 10 & 9.8 & 98 \\
\cline { 2 - 5 } & $\mathrm{Pb}$ & 10 & 6.3 & 63 \\
\cline { 2 - 5 } & $\mathrm{Ni}$ & 10 & 5.7 & 57 \\
\cline { 2 - 5 } & $\mathrm{Cu}$ & 10 & 6.8 & 68 \\
\cline { 2 - 5 } & $\mathrm{Fe}$ & 10 & 7.6 & 76 \\
\cline { 2 - 5 } & $\mathrm{Cd}$ & 10 & 5.6 & 56 \\
\hline
\end{tabular}

Table 3: Percentage Recoveries of Trace Metals in Blood using Micro wave Induced Acid Digestion Method (MWD)

\begin{tabular}{|c|l|l|l|l|}
\hline Sample & Elements & $\begin{array}{l}\text { Amount Spiked } \\
(\mu \mathrm{g} / \mathrm{mL})\end{array}$ & $\begin{array}{l}\text { Amount } \\
\text { Recovered } \\
(\mu \mathrm{g} / \mathrm{mL})\end{array}$ & $\begin{array}{l}\text { Percentage } \\
\text { Recovery }(\%)\end{array}$ \\
\hline \multirow{4}{*}{ Blood } & $\mathrm{Zn}$ & 10 & 9.9 & 99 \\
\cline { 2 - 5 } & $\mathrm{Pb}$ & 10 & 9.2 & 92 \\
\cline { 2 - 5 } & $\mathrm{Ni}$ & 10 & 9.9 & 99 \\
\cline { 2 - 5 } & $\mathrm{Cu}$ & 10 & 8.9 & 89 \\
\cline { 2 - 5 } & $\mathrm{Fe}$ & 10 & 9.4 & 94 \\
\cline { 2 - 5 } & $\mathrm{Cd}$ & 10 & 7.9 & 79 \\
\hline
\end{tabular}

\section{RESULTS AND DISCUSSION}

The results of the recovery experiment for blood samples using the conventional wet acid digestion method were obtained as percentage recoveries of $\mathrm{Cd}, \mathrm{Cu}, \mathrm{Fe}, \mathrm{Ni}, \mathrm{Pb}$ and $\mathrm{Zn}$ and are presented in Tables 1 and 2.The percentage recoveries of these elements using convectional wet acid digestion method ranged from $56 \% \mathrm{Cd}$ to $98 \% \mathrm{Zn}$. For microwave induced acid digestion method (Table 2) the percentage recoveries of the elements ranged from $79 \% \mathrm{Cd}$ to $99 \% \mathrm{Zn}$ and $\mathrm{Ni}$ respectively. The conventional wet acid digestion method can be said to be very efficient, because the percentage recovery of up to $98 \%$ but it is time consuming while the more high percentage recoveries and the short time required in the microwave induced acid digestion method make it to be a more efficient method than the conventional wet acid method. The conventional wet acid digestion method is time consuming while the MWD method saves time, less than four minutes are required to complete the digestion of the biological samples in this study. Hot plate dissolution procedures are limited by several factors: long dissolution times, the potential loss of volatile elements, sample contamination by excessive amounts of reagents and prolonged contact with vessel materials (Kingston and Walter, 1998). Cezar et al. (2010) found out that microwave - assisted digestion in closed vessels is important for minimizing the generation of laboratory residues and improving limits of detection. Similarly, Marijana and Maja (1998) compared two methods for destruction of biological material for selenium (Se) analysis: wet digestion by conductive heating in programmed digestion block and digestion in microwave oven. The results have shown that both methods are convenient for complete mineralization and are accurate in determining selenium in a variety of foodstuffs. Microwave digestion, however, has the advantage of speed and simplicity over the conventional heating procedure.

Krachler et al. (1996) suggested that a useful alternative to the hot plate is microwave heating, which is now the dominant digestion method for human samples because it is more reproducible, more accurate and less time consuming than conventional digestions on hot plates. Microwave systems keep blank levels low because only small volumes of reagents are required, and they allow more samples to be processed per hour than conventional digestion systems. In microwave method digestion takes place in sealed quartz or Teflon bombs by heating in a microwave oven. The high internal pressure that develops ensures rapid digestion without any loss of analyte. Very little acid is lost during digestion so acid consumption can be limited and the blank kept minimal.

In a multi-element analysis of Tinishu Akaki river sediments, Ethiopia, by ICP-MS after microwave assisted digestion, Melaku et al. (2005) were able to developed methods for multi-element analysis of sediment samples after the microwave digestion process they selected present considerable advantages, which include good precision and accuracy, reduced contamination, speed and safety. Pougnet (1993) successfully modified commercial microwave oven and make it safe for laboratory applications. Microwave-assisted solvent extraction of chlorinated residues from soil was found to yield recoveries equal to or exceeding recoveries attained using current EPA methods with a significant reduction in solvent usage and time as discovered by Fish and Robert, 1996. When Danny et al. (1999) compares microwave digestion of fish tissue with the commonly used method of ashing tissue in a muffle furnace, it was discovered that microwave digestion produced significantly higher phosphorus recoveries 
and took only half the time to run the same number of samples compared to ashing. Mike et al. (2005) summarised the benefits of micro wave chemistry as: Increased rate of reactions- Compared to conventional heating, microwave heating enhances the rate of certain chemical reactions by 10 to 10000 times. This is due to its ability to substantially increase the temperature of a reaction, for instance, synthesis of fluorescein, which usually takes about 10 hours by conventional heating methods, can be conducted in only 35 minutes by means of microwave heating.

Efficient source of heating- Heating by means of microwave radiation is a highly efficient process and results in significant energy saving. This is primarily because microwaves heat up just the sample and not the apparatus, and therefore energy consumption is less. A typical example is the use of microwave radiation in the ashing process. As microwave ashing systems can reach temperatures of over $800^{\circ} \mathrm{C}$ in 50 minutes, they eliminate the lengthy heating-up periods associated with conventional electricalresistance furnaces. This significantly lowers average energy cost.

Higher yields- In certain chemical reactions, microwave radiation produces higher yields compared to conventional heating methods, for example, microwave synthesis of fluorescein results in an increase in the yield of the reaction, from $70 \%$ to $82 \%$.

Uniform heating- Microwave radiation, unlike conventional heating methods, provides uniform heating throughout a reaction mixture.

Selective heating- This is based on the principle that different materials respond differently to microwaves. Some materials are transparent whereas others absorb microwaves. Therefore, microwaves can be used to heat a combination of such materials, for example, the production of metal sulphide with conventional heating requires weeks because of the volatility of sulphur vapours. Rapid heating of sulphur in a close tube results in the generation of sulphur fumes, which can cause an explosion. However, in microwave heating, since sulphur is transparent to microwaves, only the metal gets heated. Therefore, reaction can be carried out at a much faster rate, with rapid heating, without the threat of an explosion.

Environmentally-friendly chemistry- Reactions conducted in microwave are cleaner and more environmentally friendly than conventional heating methods. Microwaves heat the compounds directly; therefore, usage of solvents in the chemical reaction can be reduced or eliminated. The use of microwaves can also reduce the amount of purification required for the end products of chemical reactions involving toxic reagents.

Greater reproducibility of chemical reactionsReactions with micro wave heating are more reproducible compared to conventional heating because of uniform heating and better control of process parameters. The temperature of chemical reactions can also be easily monitored. This is of particular relevance in the lead optimization phase of the drug development process in pharmaceutical companies.

Conclusions: The efficiency of extraction of trace metals using conventional wet acid digestion method (CDM) and microwave induced acid digestion method (MWD) was determined by recovery experiments. Levels of trace metals were determined using Atomic Absorption Spectrophotometry. The high percentage recoveries, more reproducible, more accurate and less time consuming from MWD made it a more efficient method than the CDM and hence its adoption for sample digestion.

\section{REFERENCES}

Ananth, NR (2005). Trace elements estimation: Methods and clinical Context, Online J Health Appl Scie, 4: 2 - 3.

Barany, E; Bergdahl, IA; Bratteby, LE; Schütz, A; Skerfving, S; Oskarsson, A (2002). Trace element levels in whole blood and serum from Swedish adolescents. Scie Total Envi. 286: 129 141

Becking, GC; Nordberg, M; Nordberg, GF (2007). Essential metals: Assessing risks from deficiency and toxicity. In: Nordberg GF; Fowler, BA; Friberg, LT (ed) Handbook on the Toxicology of Metals, Elsevier, 163-176.

Cezar, AB; Erico, MF; Rochele, SP; Juliano, SB; Joaquim, AN (2010). Microwave-assisted digestion in closed vessels: effect of pressurization with oxygen on digestion process with diluted nitric acid, Anal Methods 2: 734 738

Danny, KT; Edward, NL; John, CB (1999). Microwave digestion method for phosphorus determination of fish tissue, Limnol. Oceanogr., 44(3): 708-709

Fish JR; Robert R (1996). Microwave solvent extraction of chlorinated pesticides from soil, LC-GC 14(3): 230-234

Guidotti, TL; McNamara; Moses, MS (2008). The interpretation of trace metals analysis in body fluid, Indian J Med Res, 128: 524 - 532. 
Kingston, HM; Walter, PJ (1998). The art and science of microwave sample preparations for trace and ultra trace elemental analysis. In: Montaser A; ed, Inductively coupled mass spectrometry, Whiley-VCH, New York, 33-81

Lindh, AT; (2005). Trace metals metabolic functions, Clinic in endocrinology and metabolism, 15: 516

Marijana, MA; Maja B (1998). Comparison of two methods for destruction of biological material for determination of selenium, Arh hig rada toksikol, 49 (4): $301-305$

Memon, AR; Tasneem, GK; Hassan, IA; Nasreen, S (2007). Evaluation of Zinc status in whole blood and scalp hair of female cancer patients, Clinica Chimica Acta. 10564

Michael, K (2003). Traces of environmental chemicals in the human body, American Council on Science and Health. Washington, 231-232

Mike, T; Shuwan, SA; Gonal, M (2005). Development in microwave chemistry, Evalueserve, 11-15
Ogunfowokan, AO; Kaisam, JP; Balogun, MO (2009). Study of trace metals in urine of some Nigerian medical patients. Tox Envi Chem, 91: $435-449$

Ogunfowokan, AO; Kaisam, JP; Balogun, MO; Adelusola, KA (2008) Analysis of $\mathrm{Cd}, \mathrm{Cu}, \mathrm{Pb}$, $\mathrm{Zn}, \mathrm{Hg}$ and $\mathrm{Mn}$ in Kidneys and liver from human cadavers- A Case Study in South Western Nigeria, Tox Env Chem, 90: 653 - 662

Pougnet MAB (1993). Modification of a commercial microwave oven for applications in the chemical laboratory, Rev Sci Instrum 64 (2): 529-531

Thomas RJ (2002). Clinical atomic spectroscopy: Determining the link between trace metals and human disease, Today's Chemists at Work, 11: $37-42$

Yenagisawa H; Wada Q (2002). Biomedical research on trace element, Indian Academy of Clinical Medicine, 13: 106 